\title{
Non-cardiogenic Pulmonary Edema and Life-Threatening Shock Due to Calcium Channel Blocker Overdose: A Case Report and Clinical Review
}

\author{
Tauseef Afaq Siddiqi MD, Jennifer Hill MD, Yvonne Huckleberry PharmD BCPS, \\ and Sairam Parthasarathy MD
}

\begin{abstract}
Calcium channel blockers (CCBs) overdose can be life-threatening when manifest as catastrophic shock and non-cardiogenic pulmonary edema. We describe a case of massive overdose of multiple medications, including sustained-release verapamil, which was resistant to conventional support. Initial treatment for CCB overdose is primarily supportive, and includes fluid resuscitation. The mechanism of non-cardiogenic pulmonary edema is not well known, and reported cases have been successfully treated with mechanical ventilation. Circulatory shock may fail to respond to atropine, glucagon, and calcium in severely poisoned patients, and vasopressors are usually required. Attempting to overcome calcium-channel antagonism with the supra-therapeutic doses of calcium salts is clinically indicated to reverse hypotension and bradycardia. There is evidence that hyperinsulinemia-euglycemia therapy is superior to other therapies for $\mathrm{CCB}$ poisoning, and the mechanism is thought to be the insulin-mediated active transport of glucose into the cells, which counters the CCB-induced intra-cellular carbohydrate-deficient state. Conventional decontamination measures are ineffective in accelerating clearance of CCB. Experience with intravenous lipid emulsion for lipophilic drug overdose, such as verapamil, is limited, but has been proposed as a rescue therapy and might improve cardiac inotropy through intravascular sequestration of the lipophilic CCB. Key words: calcium channel blockers; overdose; shock; toxicology; verapamil; hyperinsulinemia; euglycemia therapy; intravenous lipid emulsion; ARDS; pulmonary edema. [Respir Care 2014;59(2):e15-e21.

(C) 2014 Daedalus Enterprises]
\end{abstract}

\section{Introduction}

Calcium channel blockers (CCB) are antihypertensive and atrioventricular nodal blocking agents that are widely available and commonly prescribed. Taken in large doses

\footnotetext{
Drs Siddiqi, Hill, and Parthasarathy are affiliated with the Division of Pulmonary, Allergy, Critical Care, and Sleep Medicine, and Dr Huckleberry is affiliated with the Department of Pharmacy, University of Arizona, Tucson, Arizona.
}

The authors have disclosed no conflicts of interest.

Correspondence: Tauseef Afaq Siddiqi MD, Division of Pulmonary, Allergy, Critical Care, and Sleep Medicine, Arizona Health Sciences Center, 1501 N Campbell Avenue, PO Box 245030, Tucson AZ 85724-5030. E-mail: tafaq@deptofmed.arizona.edu.

DOI: $10.4187 /$ respcare.02244 these drugs can lead to catastrophic cardiovascular collapse. Verapamil and diltiazem are lipophilic, non-dihydropyridine CCBs that have particular cardioselectivity, and are more toxic than dihydropyridine antagonists (such as amlodipine and nifedipine). While CCB overdose is rare, it is often lethal, and the optimal therapy remains unclear. In 2008 the American Association of Poison Control Centers reported 2,491,049 human overdose cases. CCB were responsible for 10,398 cases $(0.4 \%)$, resulting in 12 deaths and 63 events that were life-threatening and/or resulted in substantial residual disability or disfigurement. ${ }^{1}$ Potential complications of overdose include stroke, hyperglycemia, bowel ischemia, non-cardiogenic pulmonary edema, and cardiovascular collapse.

Traditionally, treatment of CCB overdose has been primarily supportive; however, more recently intravenous lipid emulsion therapy has been used. Lipid infusions have been postulated to sequester lipophilic drugs such as verapamil, 
Non-Cardiogenic Pulmonary Edema and Life-Threatening Shock

Table 1. Laboratory Values*

\begin{tabular}{|c|c|c|c|c|}
\hline & $\begin{array}{c}\text { At } \\
\text { Presentation }\end{array}$ & $\begin{array}{l}12 \text { Hours } \\
\text { After } \\
\text { Presentation }\end{array}$ & $\begin{array}{l}24 \text { Hours } \\
\text { After } \\
\text { Presentation }\end{array}$ & $\begin{array}{l}\text { Normal } \\
\text { Range }\end{array}$ \\
\hline Sodium, $\mathrm{mMol} / \mathrm{L}$ & 138 & 142 & 145 & $136-145$ \\
\hline Potassium, mMol/L & 3.8 & 4.2 & 3.4 & $3.5-5.1$ \\
\hline Chloride, $\mathrm{mMol} / \mathrm{L}$ & 104 & 113 & 118 & $101-111$ \\
\hline Carbon dioxide, $\mathrm{mMol} / \mathrm{L}$ & 18 & 9 & 19 & $20-29$ \\
\hline Blood urea nitrogen, $\mathrm{mg} / \mathrm{dL}$ & 9 & 16 & 10 & $9-26$ \\
\hline Creatinine, $\mathrm{mg} / \mathrm{dL}$ & 0.9 & 2.0 & 1.3 & $0.7-1.3$ \\
\hline Glucose, mg/dL & 233 & 285 & 76 & $70-105$ \\
\hline Calcium, mg/dL & 10.1 & 9.9 & 13.6 & $8.6-10.6$ \\
\hline Magnesium, mg/dL & & 3.1 & 1.4 & $1.6-2.6$ \\
\hline Phosphorus, mg/dL & & 3.0 & 1.2 & $2.3-4.7$ \\
\hline Carbamazepine, $\mu \mathrm{g} / \mathrm{mL}$ & 3.8 & 16.5 & 21.2 & $4-12$ \\
\hline Salicylate, $\mu \mathrm{g} / \mathrm{mL}$ & $<20$ & & & $<20$ \\
\hline Acetaminophen, $\mu \mathrm{g} / \mathrm{mL}$ & $<6$ & & & $<6$ \\
\hline Ethanol, mg/dL & 279 & & & Undetected \\
\hline Creatine kinase, IU/L & & 75 & 387 & $30-200$ \\
\hline Troponin I, ng/mL & & 0.03 & 0.63 & $0.00-0.02$ \\
\hline $\mathrm{pH}$ & & 7.06 & 7.42 & $7.35-7.45$ \\
\hline $\mathrm{P}_{\mathrm{CO}_{2}}, \mathrm{~mm} \mathrm{Hg}$ & & 40 & 31 & $35-45$ \\
\hline $\mathrm{P}_{\mathrm{O}_{2}}, \mathrm{~mm} \mathrm{Hg}$ & & 85 & 84 & $70-95$ \\
\hline $\mathrm{S}_{\mathrm{aO}_{2}}, \%$ & & 95.6 & 95 & $94-98$ \\
\hline Calculated bicarbonate, mMol/L & & 11.3 & 20 & $22-26$ \\
\hline Ionized calcium, mMol/L & & 1.35 & 1.98 & $1-1.18$ \\
\hline Lactate, $\mathrm{mMol} / \mathrm{L}$ & & 7.6 & 3.8 & $0.5-2.2$ \\
\hline
\end{tabular}

and consequently to reduce their volume of distribution in the tissues. Additionally, hyperinsulinemia-euglycemia therapy and glucagon infusions have been used in these cases in an effort to improve cardiac utilization of glucose and myocardial contractility in the presence of profound and refractory shock. ${ }^{2-5}$

We describe a case of massive intentional overdose of multiple medications, including sustained-release verapamil, which proved resistant to conventional support, including fluid replacement, vasopressor, and inotropic agents, and required mechanical ventilation for noncardiogenic pulmonary edema. Our patient was successfully treated with mechanical ventilation, hyperinsulinemia-euglycemia, glucagon, intravenous calcium and bicarbonate, activated charcoal, and intravenous lipid therapy.

\section{Case Report}

A 40-year-old male with a history of obesity (body mass index $38.5 \mathrm{~kg} / \mathrm{m}^{2}$ ), polysubstance abuse, major depression, and hypertension was brought to the emergency department by paramedics after a suicide attempt that involved a multiple-drug overdose of unclear nature and amount. The patient was found unconscious on the floor when the paramedics responded to his spouse's call at a remote rural home, approximately 3 hours post-ingestion. In the emergency department the patient was intoxicated but hemodynamically stable, with a blood pressure of $110 / 70 \mathrm{~mm} \mathrm{Hg}$ and a heart rate of 97 beats/min. Physical examination was unremarkable, and he was sedated, yet easily arousable and oriented. Initial electrocardiogram revealed normal sinus rhythm, without PR or QTc prolongation, and no changes suggestive of ischemia. Laboratory investigations included serum chemistry, complete blood count, and liver function tests, which were all normal, with the exception of bicarbonate (Table 1). Initial chest radiography showed bibasilar atelectasis.

He was treated with $1 \mathrm{~L}$ of normal saline in the emergency department, and became more awake and less inebriated. He appeared to be sufficiently stable to be evaluated by psychiatry, and was awaiting placement in a hospital bed while being closely monitored in the emergency department. Nine hours after admission (12 h post-ingestion) he became hypotensive and lethargic. His wife indicated that he may have consumed sustained-release verapamil 


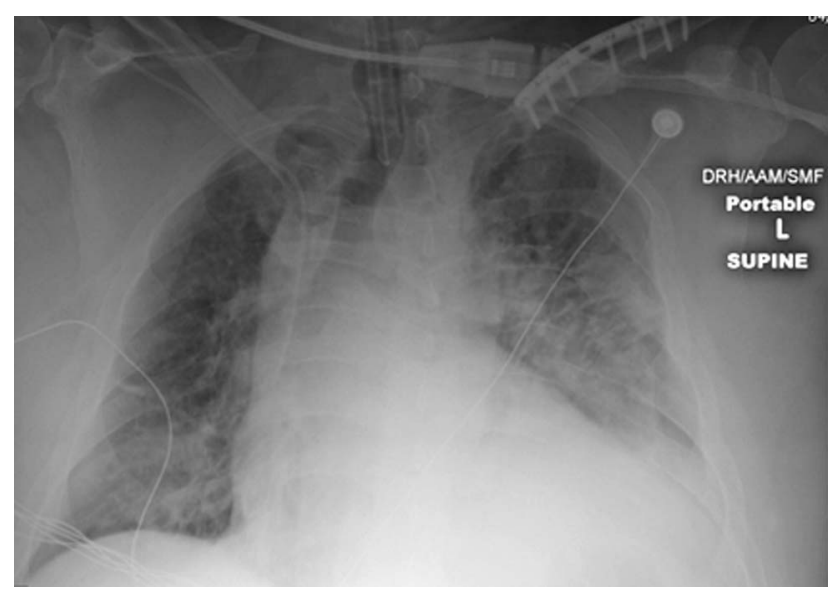

Fig. 1. Portable chest $\mathrm{x}$-ray shows non-cardiogenic pulmonary edema and atelectasis.

(3.6 g), fluoxetine (400 mg), sustained-release carbamazepine $(1,800 \mathrm{mg})$, and an unknown quantity of alcohol. Other possible co-ingestions included (all of unknown amount): sustained release oxycodone, amlodipine, valsartan, simvastatin, metformin, and trazodone. The intensive care team was immediately notified, and toxicology was consulted. At this point his blood pressure was 65/ $32 \mathrm{~mm} \mathrm{Hg}$, heart rate 76 beats/min, breathing frequency 22 breaths/min, and oxygen saturation $95 \%$ on $\mathrm{F}_{\mathrm{IO}_{2}}$ of 1.0. He received $5 \mathrm{~L}$ of normal saline over a $30-\mathrm{min}$ period, without improvement. Intravenous norepinephrine (at $10 \mu \mathrm{g} / \mathrm{min}$ ) and epinephrine (at $5 \mu \mathrm{g} / \mathrm{min}$ ) were initiated, but he remained in shock and with worsening respiratory distress and hypoxemia. A $200 \mathrm{~mL}$ intravenous bolus of $20 \%$ intralipid solution (5 mg glucagon and $4 \mathrm{~g}$ of $10 \%$ calcium chloride) was administered, then $10 \%$ calcium chloride infusion (at $0.2 \mathrm{~mL} / \mathrm{kg} / \mathrm{h}[2.7 \mathrm{~g} / \mathrm{h}]$ ) was started, and ionized calcium level was measured every hour.

Rapid-sequence intubation for obtundation and respiratory distress was performed, using etomidate $(20 \mathrm{mg})$ and succinylcholine $(100 \mathrm{mg})$, during which he aspirated some regurgitated stomach contents. He was placed on volumecontrolled continuous mandatory ventilation, with initial settings of: tidal volume $600 \mathrm{~mL}$, PEEP $5 \mathrm{~cm} \mathrm{H} \mathrm{H}_{2} \mathrm{O}, \mathrm{F}_{\mathrm{IO}_{2}} 1.0$. He was sedated with intravenous midazolam $(2-10 \mathrm{mg} / \mathrm{h}$ ) and fentanyl $(25-100 \mu \mathrm{g} / \mathrm{h})$. At that point, arterial blood analysis revealed a $\mathrm{P}_{\mathrm{aO}_{2}} / \mathrm{F}_{\mathrm{IO}_{2}}$ of $85 \mathrm{~mm} \mathrm{Hg}$, and chest radiograph was consistent with early pulmonary edema (Fig. 1). Bedside echocardiograph revealed a hyperdynamic left ventricle, an ejection fraction of $70 \%$, and no regional wall motion abnormalities. The ventilator settings were adjusted to tidal volume $500 \mathrm{~mL}(6 \mathrm{~mL} / \mathrm{kg}$ ideal body weight) and PEEP $10 \mathrm{~cm} \mathrm{H}_{2} \mathrm{O}$, based on the lungprotective strategy for severe ARDS. Plateau pressure was decreased to $30 \mathrm{~cm} \mathrm{H}_{2} \mathrm{O}$, and we were able to bring down $\mathrm{F}_{\mathrm{IO}_{2}}$ to 0.60 .
He was then transferred to the medical ICU, where he continued to be hypotensive and required additional vasopressors, including vasopressin (intravenous infusion rate $0.03 \mathrm{U} / \mathrm{min}$ ), and phenylephrine (intravenous infusion, maximum titration up to a rate of $225 \mu \mathrm{g} / \mathrm{min}$ ). The norepinephrine and epinephrine intravenous infusions were titrated up to $120 \mu \mathrm{g} / \mathrm{min}$ and $30 \mu \mathrm{g} / \mathrm{min}$, respectively. All vasopressors were required at maximum doses, despite continuous saline boluses for refractory hypotension. He then received another dose of $200 \mathrm{~mL}$ of $20 \%$ intralipid solution. Glucose and insulin therapy was initiated with $25 \%$ dextrose infusion at $7.5 \mathrm{~g} / \mathrm{h}(30 \mathrm{~mL} / \mathrm{h})$, and regular insulin infusion at $140 \mathrm{U} / \mathrm{h}(1 \mathrm{U} / \mathrm{kg} / \mathrm{h})$ after 80 units of regular insulin loading dose. Glucagon infusion was also initiated, at $5 \mathrm{mg} / \mathrm{h}$. Insulin infusion was titrated up to $220 \mathrm{U} / \mathrm{h}(1.6 \mathrm{U} / \mathrm{kg} / \mathrm{h})$, to account for hyperglycemia and to target hemodynamic stability. Plasma glucose was checked hourly, to maintain blood sugar at around $150 \mathrm{mg} / \mathrm{dL}$. Activated charcoal therapy was initiated at $50 \mathrm{~g}$ every 4 hours, and whole bowel irrigation with polyethylene glycol was commenced at $2 \mathrm{~L} / \mathrm{h}$ through a nasogastric tube (12 $\mathrm{h}$ post-ingestion).

Over the next 24 hours he developed acute oliguric kidney injury and combined anion gap and normal anion gap metabolic acidosis, so bicarbonate intravenous infusion was initiated. Creatine kinase peaked at 387 IU/L. Repeat electrocardiogram demonstrated first-degree atrioventricular block, with a ventricular rate of 97 beats $/ \mathrm{min}$, prolonged QTc of $456 \mathrm{~ms}$, and ST segment depression and $\mathrm{T}$ wave inversions at the inferior and lateral leads (Fig. 2). Troponin I peaked at $0.63 \mathrm{ng} / \mathrm{mL}$ over 24 hours and was attributed to a type II non-ST segment elevation myocardial infarction secondary to hypotension. Serum carbamazepine peaked at $22.7 \mu \mathrm{g} / \mathrm{mL}$.

On the second day in the medical ICU his oxygen requirement increased acutely, and repeat chest radiograph showed 4-quadrant air-space filling shadows suggestive of non-cardiogenic pulmonary edema, with superimposed bibasilar infiltrates. He was diuresed with intravenous furosemide and treated with intravenous piperacillin/ tazobactam for aspiration pneumonia. By the morning of the second ICU day he was successfully weaned off all vasopressors, and the glucagon infusion was discontinued. The calcium chloride infusion was discontinued once ionized calcium reached $2 \mathrm{mmol} / \mathrm{L}$. The insulin infusion was discontinued on the third ICU day. He did not require hemodialysis for carbamazepine intoxication, as the drug level gradually declined following the administration of activated charcoal, and the prolonged QTc normalized. Serum electrolytes were closely monitored and replaced, and by the third ICU day his kidney function normalized.

His hospital course was complicated by acute alcohol and opiate withdrawal on the third day, which warranted propofol infusion (up to $70 \mu \mathrm{g} / \mathrm{kg} / \mathrm{min}$ ), benzodiazepines, 


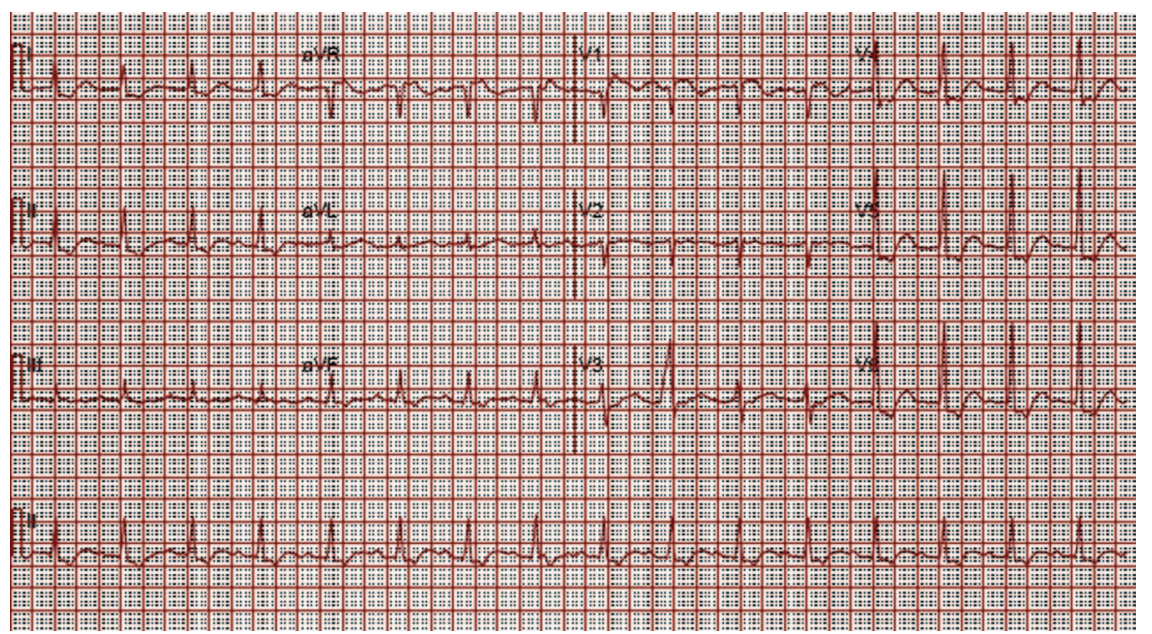

Fig. 2. Electrocardiogram shows sinus rhythm with first degree atrioventricular block, prolonged QTc interval (456 ms) and extensive ST-T wave changes.

and methadone. Anti-hypertensives, including lisinopril, metoprolol, and hydralazine, were re-initiated to control elevated blood pressure. The ventilator settings were adjusted based on plateau pressure, lung compliance, and oxygenation. He was liberated from the ventilator on the seventh hospital day, and subsequently discharged to an in-patient psychiatric facility. Comprehensive toxicology blood analysis (via gas chromatography) and urine (via thin-layer chromatography) returned positive for verapamil, ethanol, carbamazepine, oxycodone, another opiate metabolizing via morphine, and nicotine. Interestingly, although there was report of possible amlodipine ingestion, there was no other CCB identified.

\section{Discussion}

Calcium plays a central role in cardiovascular function. Cardiac function, including conduction and contraction, as well as maintenance of vascular tone in the peripheral vasculature, requires the flow of calcium across cell membranes. CCB blocks the flow of calcium through L-type calcium channels in the myocardium, vascular smooth muscle, and pancreatic $\beta$ cells. Interruption of calcium fluxes leads to decreased intracellular calcium, producing hypoinsulinemia, negative inotropic and chronotropic actions, and in severe poisoning may lead to profound bradycardia and cardiovascular shock. . $^{6} 8$

Very few cases of non-cardiogenic pulmonary edema related to overdose of verapamil, a non-dihydropyridine $\mathrm{CCB}$, have been reported in the literature. ${ }^{2,9,10}$ The mechanism of the non-cardiogenic pulmonary edema is not well known, but a possible mechanism is pre-capillary vasodilatation, resulting in excessive pulmonary capillary transudation. ${ }^{3}$ Concomitant administration of crystalloids for the refractory shock might aggravate such increased trans- udation and worsen the non-cardiogenic pulmonary edema. Prompt institution of mechanical ventilation and aggressive management of the shock is vital, as is the recognition of CCB overdose as the cause of the non-cardiogenic pulmonary edema, when adequate history is unavailable.

ARDS is a syndrome of diffuse alveolar inflammation and damage leading to increased pulmonary vascular permeability. The Berlin definition proposed mild, moderate, and severe stages of ARDS, based on degree of hypoxemia $\left(\mathrm{P}_{\mathrm{aO}_{2}} / \mathrm{F}_{\mathrm{IO}_{2}}<100,200\right.$, and $300 \mathrm{~mm} \mathrm{Hg}$, respectively). Worse severity is associated with worse mortality, and with longer mechanical ventilation among survivors. ${ }^{11}$ The ARDS Network study showed mortality benefit with lower tidal volume $(6 \mathrm{~mL} / \mathrm{kg}$ of ideal body weight) and keeping plateau pressure below $30 \mathrm{~cm} \mathrm{H}_{2} \mathrm{O}$. PEEP should be adjusted to optimize alveolar recruitment without causing over-distention. ${ }^{12}$ Lung-protective ventilation improves short-term and long-term mortality. ${ }^{13}$ Our patient developed severe ARDS related to non-cardiogenic pulmonary edema and aspiration pneumonitis. He was promptly treated with lung-protective mechanical ventilation and was successfully liberated from the ventilator in 7 days.

CCB can be divided into 2 major classes: dihydropyridines and non-dihydropyridines. The dihydropyridine class includes amlodipine and nifedipine, which have a high vascular selectivity and a powerful systemic vasodilator effect that can lead to reflex tachycardia and increased inotropy. Non-dihydropyridine class drugs include phenylalkylamine, verapamil, benzothiazepine/diltiazem, which have selectivity for both vascular and myocardium calcium channels and tend to produce hypotension, bradycardia, and conduction disturbances. In our patient the absence of early substantial bradycardia or conduction abnormalities, with occasional tachycardia, was thought to be potentially explained by the concomitant overdose with 
dihydropyridines. CCB toxicity is often associated with substantial hyperglycemia and acidosis. The underlying mechanism of CCB-induced hyperglycemia may be decreased insulin release from pancreatic $\beta$ cells and decreased insulin sensitivity and glucose uptake by tissues, including the myocardium and vascular smooth-muscles. Such decreased glucose uptake by the myocardium and vascular smooth muscles may perpetuate reductions in cardiac inotropy and peripheral vascular resistance. The consequent shock due to the aforementioned mechanisms can contribute to profound metabolic acidosis. ${ }^{7-9}$

Initial management of critically ill patients involves supportive care to ensure airway protection, adequate breathing, and circulation. However, maintenance of adequate circulation in patients with CCB overdose often also requires intravenous fluids, vasopressors, inotropes, calcium, glucagon, high-dose insulin, supplemental glucose, phosphodiesterase inhibitors, mechanical devices such as pacemakers (for refractory bradycardia and heart block), and even extracorporeal membrane oxygenation in patients with refractory shock (Fig. 3 and Table 2).,5,7 In our patient we did not have to resort to such mechanical device therapies.

There have been no controlled clinical studies demonstrating that gastrointestinal decontamination can reduce morbidity or mortality, although some case series and retrospective studies suggest that decontamination benefits some patients with CCB overdose. A recent meta-analysis of 64 controlled studies to estimate the effect of activated charcoal administered during the first 6 hours after drug ingestion found that activated charcoal is most effective when given immediately after drug ingestion, although there may be benefit even 24 hours after drug ingestion. ${ }^{14}$ The recommended dose of activated charcoal is $1 \mathrm{~g} / \mathrm{kg}$, up to $100 \mathrm{~g}$. Effectiveness of a single dose versus multiple doses is not established. A randomized controlled trial comparing no-dose to multiple-dose activated charcoal therapy found that fewer patients receiving multiple-dose activated charcoal died than those receiving no charcoal, although the difference was not statistically significant. ${ }^{15}$ Volunteer studies suggest consideration of whole bowel irrigation for patients presenting more than 2 hours after toxic ingestions of sustained-release or enteric-coated drugs. ${ }^{16}$ Our patient reportedly ingested sustained-release verapamil and carbamazepine, and was treated with both activated charcoal and whole bowel irrigation.

Initial treatment for hypotension is primarily supportive, and includes fluid resuscitation to correct vasodilation and low cardiac filling pressure. In severely poisoned patients, conventional therapies such as atropine, glucagon, and calcium often fail to improve hemodynamic status, and vasopressors are usually required to improve mean arterial pressure. Our patient needed up to 4 vasopressor agents in the first 24 hours of medical ICU admission to maintain ade-

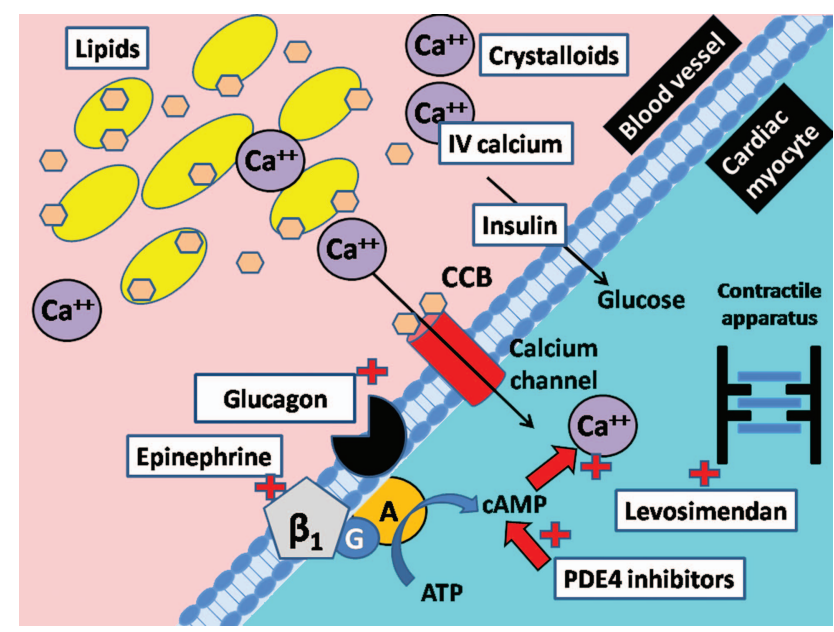

Fig. 3. Schematic of medications used to treat calcium channel blocker (CCB) poisoning, shown at the interface of a blood vessel and cardiac myocyte. Lipids (yellow) can bind the CCB and thus reduce the free CCB concentration. Intravenous (IV) calcium administration $\left(\mathrm{CA}^{++}\right)$can increase plasma concentration to try to overcome the blockage of the calcium channels (red cylinder) by CCBs. Intravenous crystalloids can be administered to combat hypotension. The $\beta_{1}$ receptor, $G$ protein $(G)$, adenyl cyclase $(A)$ complex can increase intracellular cyclic adenosine monophosphate (cAMP), which can increase intracellular calcium concentration and promote myocardial contractility. Intravenous glucagon can also increase intracellular cAMP by activating adenyl cyclase and bypassing the $\beta$ receptor (a mechanism that makes this agent useful in $\beta$-blocker poisoning as well). Phosphodiesterase inhibitors can increase cAMP concentration by reducing the breakdown by phosphodiesterase 4 . It is unclear how insulin works in CCB poisoning, but it is thought that insulin favors active transport of glucose intracellularly to make sufficient substrate available for myocardial metabolism, which is thought to suffer from a carbohydrate-deficient state during CCB poisoning. Levosimendan can in turn sensitize the contractile structures to calcium and thereby augment myocardial contractility.

quate mean arterial pressure. Catecholamines help by increasing blood pressure and heart rate, but they also increase systemic vascular resistance, which may decrease cardiac output and perfusion of vascular beds. The resultant increase in myocardial oxygen demand may prove deleterious in the setting of hypotension and decreased coronary perfusion. ${ }^{17}$

Unfortunately, conventional decontamination measures, such as urinary alkalization, hemodialysis, or hemofiltration, are ineffective in accelerating blood clearance of CCB, and there have been few efforts to develop antidotes. Injectable long-circulating liposomes bearing a transmembrane $\mathrm{pH}$ gradient have been postulated to sequester lipophilic drugs and hamper their pharmacologic effect. ${ }^{18}$ Intravenous lipid emulsion has been proposed as a rescue therapy for severe local anesthetic drug toxicity, although the experience with other lipophilic drugs, including CCB, is limited. ${ }^{19}$ The definitive mechanism of action is not known, although the "lipid sink" theory is most prevailing. 
Table 2. Treatment Options for an Overdose of Calcium Channel Blockers

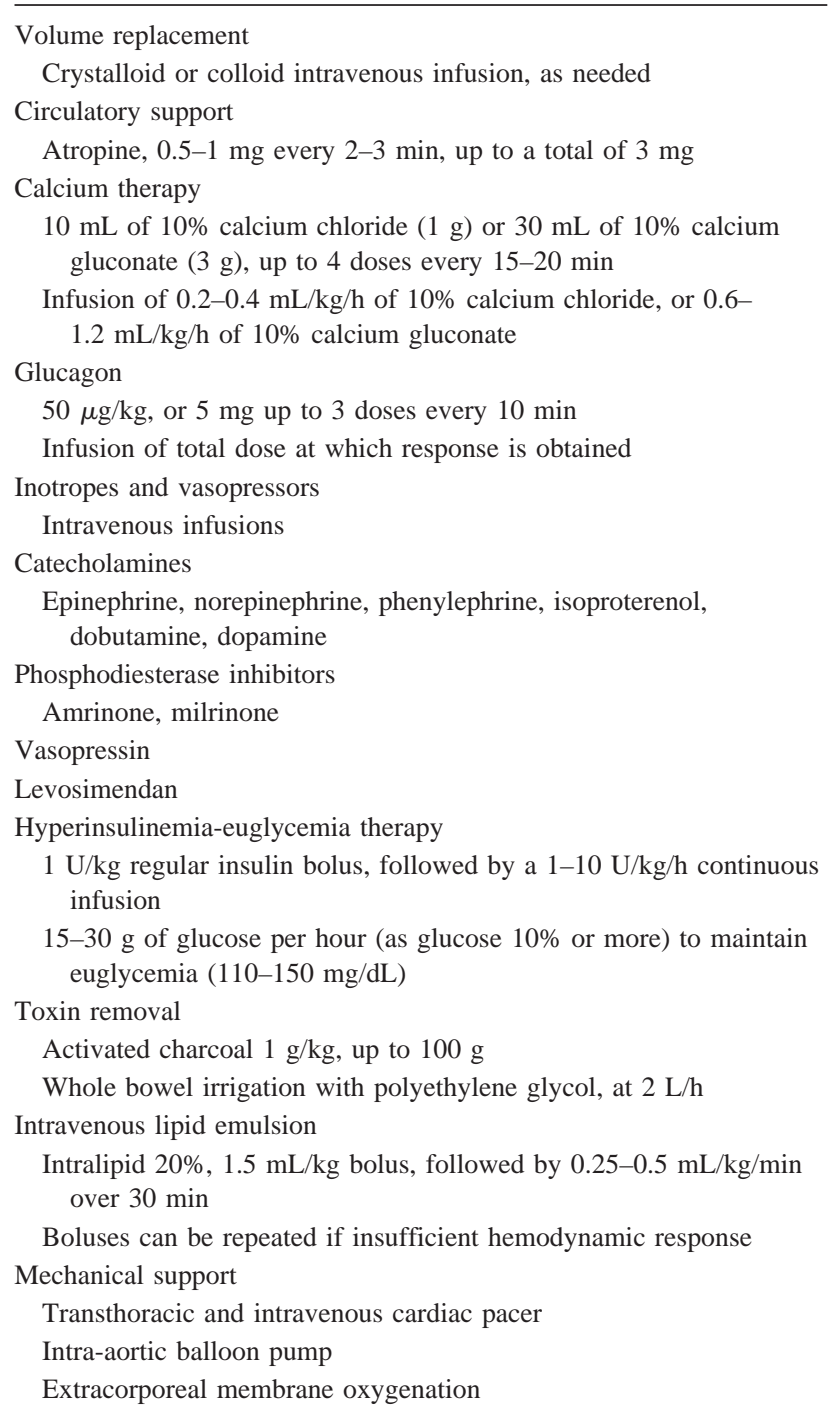

Intravenous lipid emulsion is an oil-in-water emulsion that creates an intravenous lipid phase within the plasma, which pulls the lipid-soluble drug into the lipid partition in the blood. ${ }^{20}$ An initial bolus of $1.5 \mathrm{~mL} / \mathrm{kg}$ of $20 \%$ lipid emulsion, followed by $0.25-0.5 \mathrm{~mL} / \mathrm{kg} / \mathrm{min}$ (not to exceed $10 \mathrm{~mL} / \mathrm{kg}$ ) over $30 \mathrm{~min}$, is the recommended protocol from the American Society of Regional Anesthesia. Verapamil is a lipophilic cardiotoxic drug, which could sequester in an expanded plasma lipid phase, so intravenous lipid emulsion has been proposed as a detoxifier for CCB poisoning. ${ }^{21}$ Hypertriglyceridemia and marked interference in analysis of glucose and magnesium seem to be some of a very few adverse effects due to intravenous lipid emulsion treatment. To avoid potentially harmful interventions, blood samples should be collected prior to initiating lipid therapy, and triglyceride level should be monitored. ${ }^{22}$
A recent review of the experimental and clinical data suggests that high-dose insulin (hyperinsulinemia-euglycemia) therapy is superior to conventional therapies for CCB toxicity. ${ }^{17}$ Hyperinsulinemia-euglycemia therapy is proposed to correct $\mathrm{CCB}$ overdose-related hypoinsulinemia and insulin resistance by increasing the uptake of glucose by the myocardium and vascular smooth muscle. The net effect is improved cardiac function and peripheral vascular resistance. ${ }^{23}$ The optimal dose of insulin in hyperinsulinemia-euglycemia therapy is not known. An earlier insulin dosing recommendations was $0.5 \mathrm{U} / \mathrm{kg}$ regular insulin intravenous bolus, followed by a $0.5-1 \mathrm{U} / \mathrm{kg} / \mathrm{h}$ continuous infusion, ${ }^{24}$ but clinical experience with high-dose insulin revealed improved outcomes and acceptable safety profile, so the current insulin dosing recommendation is $1 \mathrm{U} / \mathrm{kg}$ regular insulin intravenous bolus, followed by a $1-10 \mathrm{U} / \mathrm{kg} / \mathrm{h}$ continuous infusion. Higher intravenous bolus doses, up to $10 \mathrm{U} / \mathrm{kg}$ and continuous infusion up to $22 \mathrm{U} / \mathrm{kg} / \mathrm{h}$, have been reported. ${ }^{17}$ High-dose insulin therapy can cause hypoglycemia and hypokalemia by causing a shift from the extracellular space to the intracellular space, so the glucose and potassium concentrations must be closely monitored every hour, and supplementation is usually required throughout therapy and for up to $24 \mathrm{~h}$ after discontinuation of high-dose insulin. ${ }^{25}$

Supra-therapeutic doses of calcium salts have a limited effect but might help reverse hypotension and bradycardia. ${ }^{6}$ Calcium chloride (10 mL of a $10 \%$ solution, $1 \mathrm{~g}$ ) can be administered over $10 \mathrm{~min}$, and if there is no effect, the dose may be repeated up to 4 times, every 15-20 min. Calcium gluconate can also be used, although the dose must be adjusted to $30 \mathrm{~mL}$ of $10 \%$ solution $(3 \mathrm{~g})$, because calcium gluconate has only one third of the elemental calcium of calcium chloride. This can be followed by a continuous infusion of calcium at $0.5 \mathrm{mEq} / \mathrm{kg} / \mathrm{h}$, with close monitoring of ionized calcium and serial electrocardiograms.

Intravenous infusions of inotropic agents such as dobutamine or phosphodiesterase inhibitors are used for signs of heart failure or cardiogenic shock. High-dose catecholamines increase afterload, further impairing left ventricular function. Phosphodiesterase inhibitors such as milrinone and amrinone improve cardiac function because of their inotropic and vasodilation effects (amrinone is not available in the United States). ${ }^{26}$ Levosimendan is an inotropic agent that enhances myofilament response to calcium and increases myocardial contraction and could therefore be beneficial in verapamil intoxication. ${ }^{27}$ The use of levosimendan in CCB overdose is not widely accepted, and levosimendan is also not available in the United States. The recommended dose range is $3-36 \mu \mathrm{g} / \mathrm{kg}$ as intravenous bolus and $0.05-0.6 \mu \mathrm{g} / \mathrm{kg} / \mathrm{min}$ continuous infusion. ${ }^{28}$

In conclusion, $\mathrm{CCB}$ overdose requires a multi-faceted treatment and may not respond to traditional supportive 


\section{Non-Cardiogenic Pulmonary Edema And Life-Threatening Shock}

measures such as fluid replacement and vasopressor support alone. Less conventional modalities such as hyperinsulinemia-euglycemia therapy and intralipid infusions need to be administered early in patients presenting with hemodynamic instability.

\section{REFERENCES}

1. Bronstein AC, Spyker DA, Cantilena LR Jr, Green JL, Rumack BH, Giffin SL. 2008 Annual report of the American Association of Poison Control Centers' National Poison Data System (NPDS): 26th Annual Report. Clin Toxicol (Phila) 2009;47(10):911-1084.

2. Kute VB, Shah PR, Goplani KR, Gumber MR, Vanikar AV, Trivedi HL. Successful treatment of refractory hypotension, noncardiogenic pulmonary edema and acute kidney injury after an overdose of amlodipine. Indian J Crit Care Med 2011;15(3):182-184.

3. Humbert VH, Munn NJ, Hawkins RF. Noncardiogenic pulmonary edema complicating massive diltiazem overdose. Chest 1991;99(1): 258-259.

4. Patel NP, Pugh ME, Goldberg S, Eiger G. Hyperinsulinemic euglycemia therapy for verapamil poisoning: case report. Am J Crit Care 2007;16(5):518-520.

5. Shepherd G. Treatment of poisoning caused by beta-adrenergic and calcium-channel blockers. Am J Health Syst Pharm 2006;63(19): 1828-1835.

6. Howarth DM, Dawson AH, Smith AJ, Buckley N, Whyte IM. Calcium channel blocking drug overdose: an Australian series. Hum Exp Toxicol 1994;13(3):161-166.

7. DeWitt CR, Waksman JC. Pharmacology, pathophysiology and management of calcium channel blocker and beta-blocker toxicity. Toxicol Rev 2004;23(4):223-238.

8. Ramoska EA, Spiller HA, Winter M, Borys D. A one-year evaluation of calcium channel blocker overdoses: toxicity and treatment. Ann Emerg Med 1993;22(2):196-200.

9. Sami Karti S, Ulusoy H, Yandi M, Gunduz A, Kosucu M, Erol K, et al. Non-cardiogenic pulmonary oedema in the course of verapamil intoxication. Emerg Med J 2002;19(5):458-459.

10. Brass BJ, Winchester-Penny S, Lipper BL. Massive verapamil overdose complicated by noncardiogenic pulmonary edema. Am J Emerg Med 1996;14(5):459-461.

11. Ranieri VM, Rubenfeld GD, Thompson BT, Ferguson ND, Caldwell E, Fan E, et al. Acute respiratory distress syndrome: the Berlin Definition. JAMA 2012;307(23):2526-2533.

12. Hess DR. Approaches to conventional mechanical ventilation of the patient with acute respiratory distress syndrome. Respir Care 2011; 56(10):1555-1572.

13. Needham DM, Colantuoni E, Mendez-Tellez PA, Dinglas VD, Sevransky JE, Dennison Himmelfarb CR, et al. Lung protective mechanical ventilation and two year survival in patients with acute lung injury: prospective cohort study. BMJ 2012;344:e2124.

14. Jurgens G, Hoegberg LC, Graudal NA. The effect of activated charcoal on drug exposure in healthy volunteers: a meta-analysis. Clin Pharmacol Ther 2009;85(5):501-505.

15. Eddleston M, Juszczak E, Buckley NA, Senarathna L, Mohamed F, Dissanayake W, et al. Multiple-dose activated charcoal in acute selfpoisoning: a randomised controlled trial. Lancet 2008;371(9612): 579-587.

16. Frithsen IL, Simpson WM, Jr. Recognition and management of acute medication poisoning. Am Fam Physician 2010;81(3):316-323.

17. Engebretsen KM, Kaczmarek KM, Morgan J, Holger JS. High-dose insulin therapy in beta-blocker and calcium channel-blocker poisoning. Clin Toxicol (Phila) 2011;49(4):277-283.

18. Forster V, Luciani P, Leroux JC. Treatment of calcium channel blocker-induced cardiovascular toxicity with drug scavenging liposomes. Biomaterials 2012;33(13):3578-3585.

19. Young AC, Velez LI, Kleinschmidt KC. Intravenous fat emulsion therapy for intentional sustained-release verapamil overdose. Resuscitation 2009;80(5):591-593.

20. Kaplan A, Whelan M. The use of IV lipid emulsion for lipophilic drug toxicities. J Am Anim Hosp Assoc 2012;48(4):221-227.

21. Montiel V, Gougnard T, Hantson P. Diltiazem poisoning treated with hyperinsulinemic euglycemia therapy and intravenous lipid emulsion. Eur J Emerg Med 2011;18(2):121-123.

22. Grunbaum AM, Gilfix BM, Gosselin S, Blank DW. Analytical interferences resulting from intravenous lipid emulsion. Clin Toxicol (Phila) 2012;50(9):812-817.

23. Agarwal A, Yu SW, Rehman A, Henkle JQ. Hyperinsulinemia euglycemia therapy for calcium channel blocker overdose: a case report. Tex Heart Inst J 2012;39(4):575-578.

24. Boyer EW, Duic PA, Evans A. Hyperinsulinemia/euglycemia therapy for calcium channel blocker poisoning. Pediatr Emerg Care 2002; 18(1):36-37.

25. Lheureux PE, Zahir S, Gris M, Derrey AS, Penaloza A. Bench-tobedside review: hyperinsulinaemia/euglycaemia therapy in the management of overdose of calcium-channel blockers. Crit Care 2006; 10(3):212.

26. Sandroni C, Cavallaro F, Addario C, Ferro G, Gallizzi F, Antonelli M. Successful treatment with enoximone for severe poisoning with atenolol and verapamil: a case report. Acta Anaesthesiol Scand 2004; 48(6):790-792.

27. Varpula T, Rapola J, Sallisalmi M, Kurola J. Treatment of serious calcium channel blocker overdose with levosimendan, a calcium sensitizer. Anesth Analg 2009;108(3):790-792.

28. Landoni G, Biondi-Zoccai G, Greco M, Greco T, Bignami E, Morelli A, et al. Effects of levosimendan on mortality and hospitalization. A meta-analysis of randomized controlled studies. Crit Care Med 2012; 40(2):634-646 